\title{
Ingested Listeria monocytogenes survive and multiply in protozoa
}

\author{
THI MINH CHAU LY and H. E. MÜLLER
}

Staatliches Medizinaluntersuchungsamt Braunschweig, D-3300 Braunschweig, Federal Republic of Germany

Summary. Listeria monocytogenes cells are ingested by protozoa such as Acanthamoeba sp. or Tetrahymena pyriformis. However, they are not killed, but survive within the protozoa and may multiply intracellularly. The protozoa are lysed within about 8 days, releasing viable $L$. monocytogenes. No co-existence was observed between $L$. monocytogenes and Tetrahymena. A co-culture of L. monocytogenes and Acanthamoeba sp. showed a decay of locomotive forms and release of listeria from vegetative protozoan cells whereas the bacteria were destroyed in cysts. These phenomena provide an insight into the pathogenesis of listeria infection in man and warmblooded animals because intracellular processes occurring in protozoa after ingestion of $L$. monocytogenes may be similar to those observed in mammalian cells.

\section{Introduction}

Listeria monocytogenes is an ubiquitous bacteria occurring in all regions of the world. However, its ecology is unclear. ${ }^{1}$ On the one hand, the organisms have been isolated frequently from all sorts of soil samples, superficial sewage, and wastewater. ${ }^{2}$ Furthermore, they grow at temperatures as low as $4^{\circ} \mathrm{C}$. This evidence seems to point to the environment as the natural habitat of Listeria spp. On the other hand, L. monocytogenes is a pathogen, causing disease in many species of warm-blooded animals. ${ }^{3}$ Not only raw vegetables such as cabbage ${ }^{4}$ or lettuce $^{5}$ but also foods of animal origin such as meat, milk and cheese are sources of human infection. $^{2}$ However, in contrast to most other saprophytes that are occasional pathogens, but rather like some obligatory parasitic organisms, $L$. monocytogenes is able to multiply inside many host cells, e.g., in macrophages, enterocytes and hepatocytes. This is hard to understand. The known facts about the behaviour and properties as well as the ecological niche of $L$. monocytogenes cannot explain how this saprophytic, environmental organism has acquired the ability to survive within mammalian cells.

The similarity of free-living, bacteria-scavenging protozoa to macrophages suggests that protists are the missing link in the ecology and pathology of listeria. Therefore, this study was initiated to investigate the complex food chain of the two groups of organisms.

Received 24 Jan. 1990; accepted 13 March 1990.

\section{Materials and methods}

\section{Protozoa}

Acanthamoeba sp. were isolated by filtering fresh water through $3 \mu \mathrm{m}$ nitrocellulose membrane filters (SM 11302, Sartorius, Göttingen, FRG). The filters were placed on non-nutrient agar plates spread with a $0 \cdot 1-\mathrm{ml}$ suspension of heat-killed Escherichia coli $\left(10^{8} \mathrm{cfu} / \mathrm{ml}\right)$. Plates were incubated at $20^{\circ} \mathrm{C}$ for 1 week in a moist chamber. Growth of amoebae occurred after 6 days. The amoebae were cloned and a pure isolate of Acanthamoeba sp. was identified as described by Lee ${ }^{6}$ and Page. ${ }^{7}$ They were maintained on non-nutrient agar as described above.

A Tetrahymena pyriformis culture was from a stock strain grown in Diamond's medium ${ }^{6}$ at $20^{\circ} \mathrm{C}$. When needed, $T$. pyriformis organisms were collected on a $3-\mu \mathrm{m}$ nitrocellulose membrane filter, washed, and suspended in sterile tap water.

\section{Listeria monocytogenes}

L. monocytogenes was isolated from wastewater as described elsewhere. ${ }^{8,9}$ Biochemical characterisation was by standard methods. ${ }^{10-12}$ The organisms were maintained on blood agar at $20^{\circ} \mathrm{C}$. After removal from agar, pure suspensions were obtained by washing in sterile tap water.

\section{Counting}

$T$. pyriformis cells were counted by adding $0 \cdot 1 \mathrm{ml}$ of the culture to $0.05 \mathrm{ml}$ of Türk's solution (acetic acid-gentian violet solution) and $0.05 \mathrm{ml}$ distilled water and then counting the number of cells in a Neubauer chamber $\left(0.1 \mathrm{~mm} \times 0.0025 \mathrm{~mm}^{2}\right)$ under bright-field illumination at 
a magnification of 10. Acanthamoeba sp. were counted by adding $0.1 \mathrm{ml}$ of the protozoan suspension to $0.1 \mathrm{ml}$ of aqueous methylene blue $0.005 \%$ and counting as above. All preparations of protozoa were tested for the viability of ingested listeria by a fluorescent staining procedure with fluorescein diacetate. ${ }^{13,14}$ Viable $L$. monocytogenes cfus were counted on acriflavine-ceftazidime (AC) agar. ${ }^{15}$

\section{Microscopical examination}

T. pyriformis were examined by light microscopy in situ in solution in petri dishes with a Zeiss stereomicroscope DR. Acanthamoeba sp. were suspended in one drop of sterile tap water on a cover slip and examined with a Zeiss Axioscope.

\section{Co-cultivation experiments}

The interaction of L. monocytogenes with Acanthamoeba sp. and $T$. pyriformis was studied by mixing appropriate concentrations of the organisms in sterile tap water $(25 \mathrm{ml})$ and incubating at $36^{\circ} \mathrm{C}$ for up to 5 weeks. As control, a pure suspension of $L$. monocytogenes was incubated in the same conditions; similar controls with Acanthamoeba sp. and T. pyriformis were set up, although the initial concentrations of the protozoa were higher than in the co-cultivation experiments because of diffculties in counting lower numbers.

\section{Determination of phagocytosis of L. monocytogenes by protozoa}

Acanthamoeba sp. and $T$. pyriformis fed upon $L$. monocytogenes by co-cultivation during 6-8 days; they were then separated from extracellular L. monocytogenes by filtration as described above and washed with a solution of gentamicin $0.5 \mu \mathrm{g} / \mathrm{ml}$ for $1 \mathrm{~h}$. After these procedures, no extracellular viable $L$. monocytogenes were detected. The washed protozoa suspended in sterile distilled water were disrupted by ultrasonication for $10 \mathrm{~s}$. Complete disintegration of protozoa was confirmed by microscopy. However, no loss of viability of $L$. monocytogenes occurred as shown by examination of controls of bacteria without protozoa. Samples of the lysed suspensions were plated on AC agar and cfus of L. monocytogenes were counted.

All experiments were repeated several times. The figures, displayed graphically, are typical and were reproducible. However, the data obtained from different assays were not expressed numerically for statistical presentation.

\section{Results}

\section{L. monocytogenes and Acanthamoeba sp.}

Sequential counts of L. monocytogenes and Acanthamoeba sp. are shown in fig. 1. Pure suspensions of L. monocytogenes and Acanthamoeba sp. served as controls and their numbers decreased slowly and continuously. However, in co-culture, L. monocytogenes showed first a major fall to a minimum of about $1 \mathrm{cfu} / \mathrm{ml}$ around day 8 and thereafter numbers rose again. In contrast, the Acanthamoeba sp. showed inverse kinetics. First, the number of amoebae increased to reach a maximum around day 8 . Fluorescein diacetate staining showed that

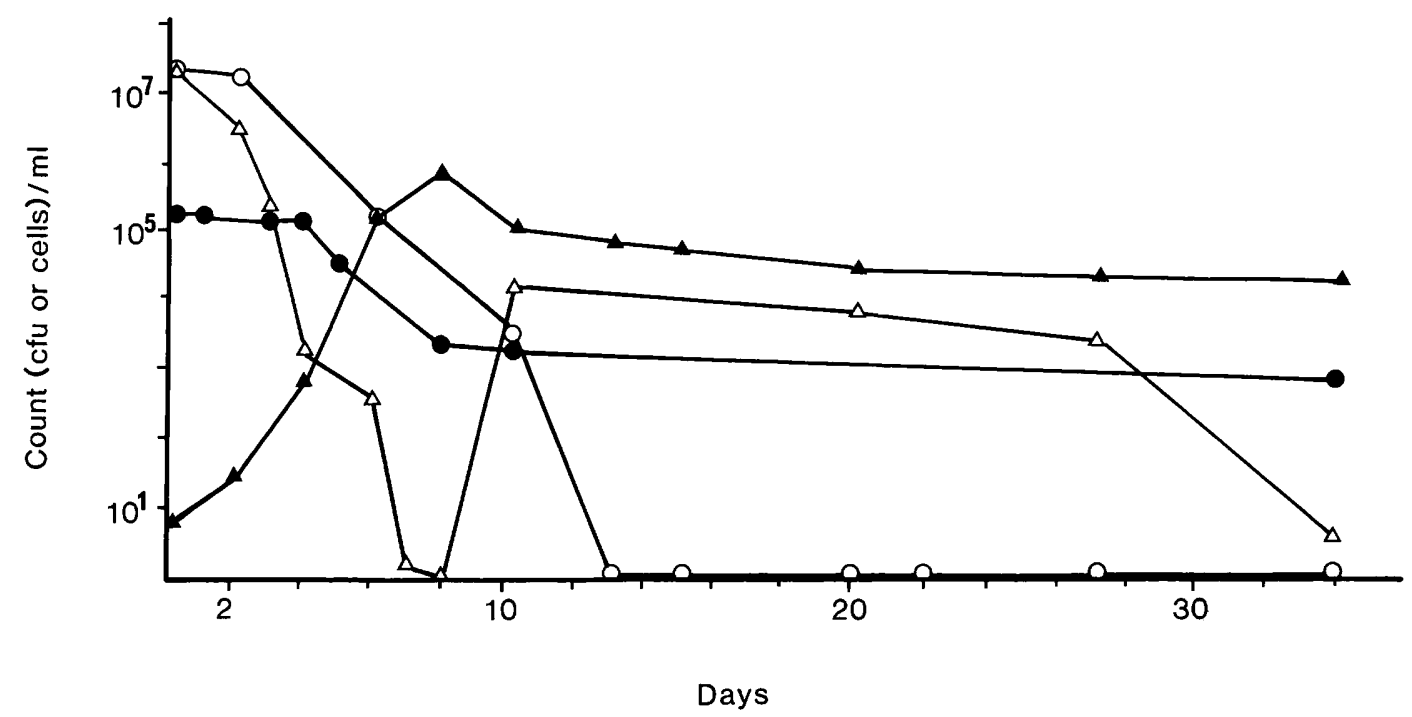

Fig. 1. Counts of L. monocytogenes (cfu/ml) and Acanthamoeba sp. (cells $/ \mathrm{ml}$ ) in co-culture and in control suspension incubated at $36^{\circ} \mathrm{C}$ for 34 days. L. monocytogenes in co-culture with Acanthamoeba sp. $\triangle ;$ Acanthamoeba sp. in co-culture with L. monocytogenes $\Delta ;$ L. monocytogenes control, $\bigcirc ;$ Acanthamoeba sp. control $\bigcirc$. 
amoebae contained hundreds of living listeria intracellularly. Viable counts of listeria from gentamicin-washed and then lysed cells of Acanthamoeba sp. confirmed the microscopic findings. Beginning on day 8, the Acanthamoeba sp. encysted, although some of the cells ruptured and released viable $L$. monocytogenes. On day 10 , about $90 \%$ of the amoebae were locomotive forms and only $10 \%$ were cysts. However, on day 34, almost all were cysts. Ingested and so far viable $L$. monocytogenes died during formation of the cysts.

\section{L. monocytogenes and T. pyriformis}

Growth kinetics of $L$. monocytogenes and $T$. pyriformis are given in fig. 2. During the first 5-7 days, $T$. pyriformis ingested all cells of $L$. monocytogenes. During this period $T$. pyriformis multiplied greatly and large numbers of aggregated cells appeared. However, in contrast to amoebae, Tetrahymena does not develop cysts. Microscopic examination of cells stained by fluorescein diacetate as well as lysis experiments showed thousands of living listeria intracellularly within one Tetrahymena cell. After 8-15 days, T. pyriformis cells lysed and released viable $L$. monocytogenes. The viable counts of L. monocytogenes now reached $10^{8} \mathrm{cfu} / \mathrm{ml}$ and were higher than the initial inoculum. Therefore, intracellular multiplication of listerias in $T$. pyriformis occurred because they did not multiply extra- cellularly. On the other hand, the population of $T$. pyriformis broke down completely within 3-5 weeks and no cells were alive after that; the L. monocytogenes also died.

\section{Discussion}

Our results show that Acanthamoeba sp. as well as $T$. pyriformis ingest $L$. monocytogenes. The bacteria survive in the protozoa, multiply at least in $T$. pyriformis and may also stimulate cell division. After some days, the infected protozoa are destroyed and release L. monocytogenes. Whereas cells of $T$. pyriformis die completely, Acanthamoeba sp. develop cysts in which $L$. monocytogenes dies. The phenomenon of intracellular multiplication of $L$. monocytogenes in protozoa is a further example of an obvious general principle: saprophytic bacteria living in environmental niches and yet pathogenic for man or animals by intracellular parasitism may be virulent by virtue of the ability to survive in the same way as they survive in and destroy protozoa.

Rowbotham observed that the pathogenicity of Legionella pneumophila is due to its ability to multiply within freshwater and soil amoebae $;^{16,17}$ L. monocytogenes shows a similar behaviour. Normally, Listeria and Legionella spp., as well as many other bacteria, serve as food for secondary feeders, i.e., protozoa, as part of the microbial food chain. However, Listeria and Legionella spp. have suc-

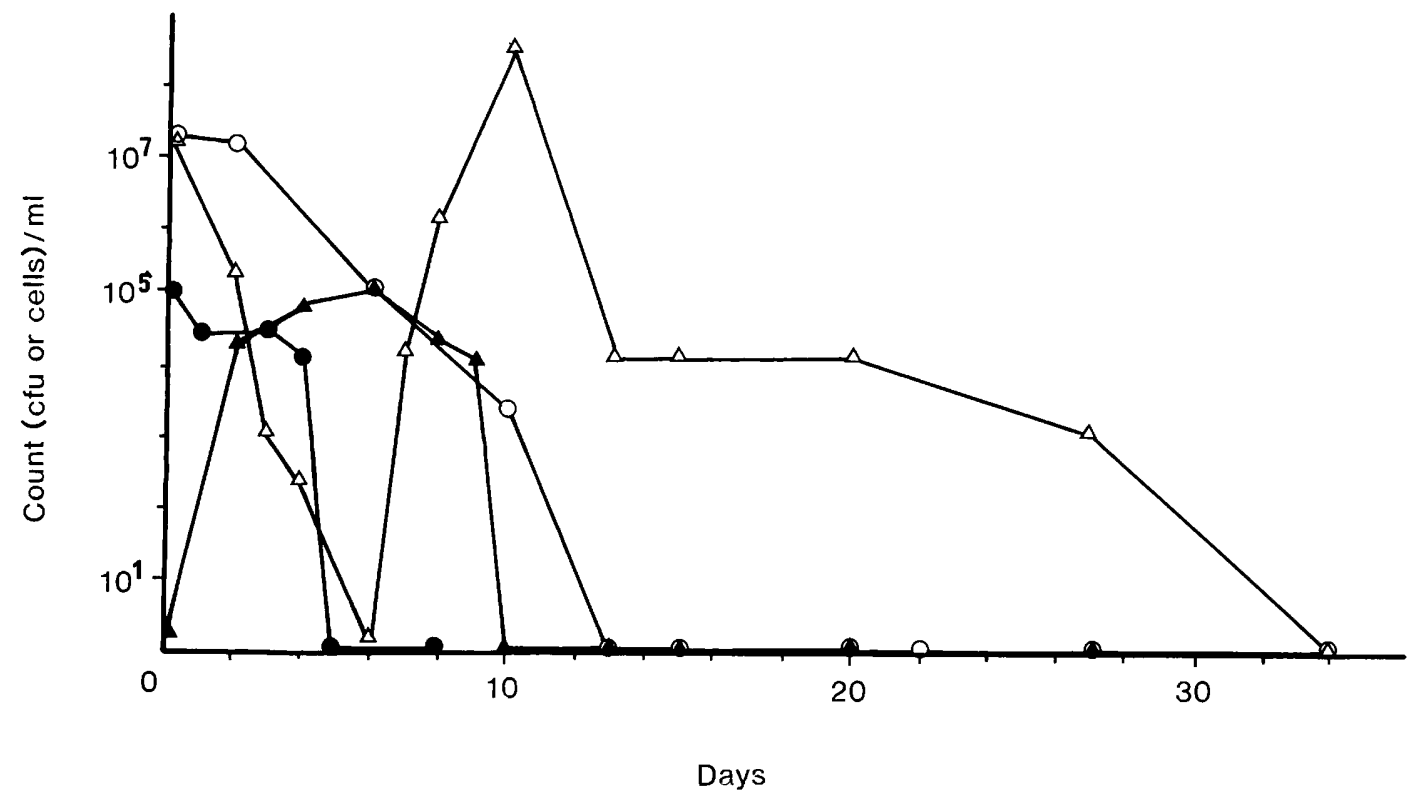

Fig. 2. Counts of $L$. monocytogenes $(\mathrm{cfu} / \mathrm{ml})$ and $T$. pyriformis $($ cells $/ \mathrm{ml})$ in co-culture and in control suspensions incubated at $36^{\circ} \mathrm{C}$ for 34 days. $L$. monocytogenes in co-culture with $T$. pyriformis $\triangle ; T$. pyriformis in co-culture with $L$. monocytogenes $\Delta ; L$. monocytogenes control $\bigcirc ; T$. pyriformis control 
ceeded in turning the tables on their predators and growing within the protozoa. Some other environmental bacteria are also intracellular pathogens of man or animals and may possess similar properties, e.g., ubiquitous non-tuberculosis mycobacteria (MOTT bacilli), possibly $M$. leprae, and Yersinia spp. ${ }^{18,19}$ Resistance to digestion by protozoa and destruction of the feeding cells give us a special insight into the pathogenesis of infections by such pathogens. Intracellular processes occurring in protozoa after ingestion of listeria may be similar to those observed in macrophages or other mammalian cells from hosts with listeriosis.

The fact that higher organisms possess abundant iron in the enzymes and functional proteins of many cells, but that such reserves are not available to a similar extent in most lower animals (e.g.,

\section{REFERENCES}

1. Müller HE. Absence of Listeria species in lower animals. Ann Inst Pasteur Microbiol 1988; 139: 727-730.

2. Anonymous. Foodborne listeriosis. Report of a WHO informal working group. Geneva, 15-19 February 1988, WHO/EHE/FOS/88.

3. Müller $\mathrm{HE}$, Listeriosis in animals. Infeksiyon Dergisi (Turkish J Infect) 1988; 2: 505-519.

4. Schlech WF, Lavigne PM, Bortolussi RA et al. Epidemic listeriosis - evidence for transmission by food. $N$ Engl $J$ Med 1983; 308: 203-206.

5. Bendig JWA, Strangeways JEM. Listeria in hospital lettuce. Lancet 1989; 1: 616-617.

6. Lee JJ, Hutner SH, Bovee EC. An illustrated guide to the protozoa. Lawrence, Kansas, Allen Press (Society of Protozoologists). 1985: 2, 184.

7. Page FC. An illustrated key to freshwater and soil amoebae. Ferry House, Ambleside, Cumbria, Freshwater Biological Association, Scientific Publication No. 34. 1976: 112.

8. Geuenich HH, Müller HE. Isolierung und Keimzahlbestimmung von Listeria monocytogenes in ungeklärtem und biologisch gereinigtem Abwasser. Zentralbl Bakteriol Mikrobiol [B] 1984; 179: 266-273.

9. Geuenich HH, Müller HE, Schretten-Brunner A, Seeliger HPR. The occurrence of different Listeria species in municipal waste water. Zentralbl Bakteriol Mikrobiol Hyg [B] 1985; 181 : 563-565.

10. Rocourt J, Catimel B. Caractérisation biochimique des espèces du genre Listeria. Zentralbl Bakteriol Mikrobiol Hyg [A] 1985; 260: 221-231.

11. Rocourt J. The recognition and identification of Listeria species by classical methods. Infeksiyon Dergisi (Turkish $J$ Infect) 1988; $2: 471-485$. insects) may explain the occurrence and pathogenicity of L. monocytogenes in warm-blooded hosts. ${ }^{3}$ Of course, the organisms produce listeriolysin $\mathrm{O}$ which is an important virulence factor 20,21 and mobilises from host cells iron which is a growth limiting factor. On the other hand, lower animals contain more copper and less iron. Therefore, they are not natural hosts of L. monocytogenes. ${ }^{1}$ Interestingly, Legionella shows a similar requirement for iron and also does not possess siderophores because they are not primary parasites of warm-blooded hosts. There is no need for siderophores to mobilise iron in their natural environment.

We acknowledge the support of the German Bundesanstalt für Arbeit (ABM-No. 96/87/211) and thank Sabine Müller and Friederike Heimbach for excellent technical assistance.

12. Seeliger HPR, Jones D. Genus Listeria Pirie $1940,383^{\mathrm{AL}}$. In: Sneath PHA, Mair NS, Sharpe ME, Holt JG (eds) Bergeys Manual of systematic bacteriology, vol. 2, Baltimore, MD, Williams and Wilkins. 1986: 12351245.

13. Kvach JT, Veras JR. A fluorescent staining procedure for determining the viability of mycobacterial cells. Int $J$ Lepr Other Mycobact Dis 1982; 50: 183-192.

14. Paton AM, Jones SM. The observation and enumeration of micro-organisms in fluids using membrane filtration and incident fluorescence microscopy. J Appl Bacteriol $1975 ; 38$ : 199-200.

15. Bannerman ES, Bille J. A new selective medium for isolating Listeria spp. from heavily contaminated material. Appl Environ Microbiol 1988; 54: 165-167.

16. Rowbotham TJ. Preliminary report on the pathogenicity of Legionella pneumophila for freshwater and soil amoebae. J Clin Pathol 1980; 33 : 1179-1183.

17. Rowbotham TJ. Current views on the relationships between amoebae, legionella and man. Isr J Med Sci 1986; 22 : 678-689.

18. Blake LA, West BC, Lary CH, Todd JR. Environmental nonhuman sources of leprosy. Rev Infect Dis 1987; 9: 562-577.

19. Collins FM, Campbell SG. Immunity to intracellular bacteria. Vet Immun Immunpathol 1982; 3: 5-66.

20. Mengaud J, Chenevert J, Geoffroy C, Gaillard JL, Cassart P. Identification of the structural gene encoding the SH-activated hemolysin of Listeria monocytogenes: listeriolysin $\mathrm{O}$ is homologous to streptolysin $\mathrm{O}$ and pneumolysin. Infect Immun 1987; 55 : 3225-3227.

21. Parrisius J, Bhakdi S, Roth M, Tranum-Jensen J, Goebel W, Seeliger HPR. Production of listeriolysin by betahemolytic strains of Listeria monocytogenes. Infect Immun 1986; 51 : 314-319. 